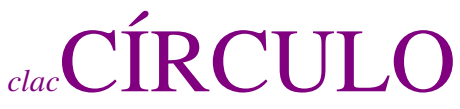 \\ de \\ linguística \\ aplicada a la \\ ción
}

$64 / 2015$

\section{ASPECTOS DE INTEGRACIÓN MULTIMODAL EN LA PRENSA DIGITAL DE TEMA JURÍDICO Y TEMA CIENTÍFICO}

\author{
Fernando Polanco Martínez e Irene Yúfera Gómez
}

Universitat de Barcelona

polanco en ub edu, iyufera en ub edu

Resumen

El paso de la prensa escrita a la prensa digital ha supuesto la posibilidad de dotar a las piezas informativas de una mayor multimodalidad, de manera que diversos modos semióticos concurren en la construcción del significado. En este trabajo queremos analizar en qué medida $-\mathrm{y}$ de qué manera- se establece la relación entre imágenes y textos en la prensa digital de especialidad de los ámbitos jurídico y científico; y si esta relación contribuye eficazmente en la cohesión multimodal de estas piezas informativas en tanto que complejos semánticos de carácter multimodal. Para ello, hemos aplicado el modelo intersemiótico propuesto por Martinec y Salway (2005) al análisis de la relación imagen-texto en 30 piezas informativas de la versión digital del periódico $A B C$. Con este modelo de análisis, queremos dar cuenta de esta relación en función del estatus que

Fernando Polanco Martínez e Irene Yúfera Gómez. 2015.

Aspectos de integración multimodal en la prensa digital de tema jurídico y de tema científico

Círculo de Lingüística Aplicada a la Comunicación 64, 32-57.

http://www.ucm.es/info/circulo/no64/polanco.pdf

http://revistas.ucm.es/index.php/CLAC

http://dx.doi.org/10.5209/rev_CLAC.2015.v64.51277

(C) 2015 Fernando Polanco Martínez e Irene Yúfera Gómez

Círculo de Lingüística Aplicada a la Comunicación (clac)

Universidad Complutense de Madrid. ISSN 1576-4737. http://www.ucm.es/info/circulo 
ocupan la imagen y el texto dentro de la pieza informativa en tanto que unidades semióticas en sí mismas y de la relación semántica entre ellas.

Palabras clave: análisis intersemiótico, análisis del discurso multimodal, artefactos multisemióticos, análisis del discurso profesional

\section{Abstract}

Aspects of multimodal integration in scientific and legal issues online news

The transition from written press to digital press provides news of greater multimodality, so that different semiotic modes concur in the construction of meaning. In this study, we want to analyse the way the relationship between images and text is realized in specialized digital press on legislative and juridical topics, and how this relationship contributes effectively to the multimodal cohesion of these news items, thus constructing complex multimodal entities. To this effect, we applied the intersemiotic model proposed by Martinec and Salway (2005) to analyse the image-text relation of 30 news items of the digital version of the newspaper $A B C$. With this model, we account for the logico-semantic and intersemiotic relationship between image and the text within the news.

Key words: Intersemiotic analysis, multimodal discourse analysis, multisemiotic artefacts, professional discourse analysis

Índice

1. Introducción, 34

2. Objetivos, 35

3. Metodología, 37

4. Análisis, 39

4.1. El modo icónico. Las palabras y los dispositivos visuales, 39

4.2. Análisis intersemiótico de la relación imagen-texto, 40

4.3. Relaciones entre imagen y texto. Combinación de estatus y semántica, 43

4.3.1. Estatus de igualdad, 43

4.3.1.1. Imagen y texto independientes, exposición, 43 
4.3.1.2. Imagen y texto independientes, ejemplificación (texto más general), 44

\subsubsection{Estatus de desigualdad, 46}

4.3.2.1. Texto subordinado a la imagen, ampliación, 46

4.3.2.2. Texto subordinado a la imagen, exposición, 48

4.3.2.3. Imagen subordinada al texto, exposición, ampliación, 48

4.3.2.4. Imagen subordinada al texto, ejemplificación y extensión, 50

4.3.2.5. Imagen subordinada al texto, proyección de ideas, 52

4.3.3. Estatus de complementariedad, 53

4.3.3.1. Texto e imagen complementarios, proyección de locución, 53

5. Conclusiones, 54

Bibliografía, 56

\section{Introducción ${ }^{1}$}

Dado el entorno multimodal (Kress 2010), interactivo e hipertextual (Salaverría 2005, Salaverría y Sancho 2007) en que se inserta la prensa digital, este soporte brinda nuevos recursos para divulgar realidades complejas que se añaden a los mecanismos lingüístico-discursivos de divulgación. Entre ellos cabe destacar los que pueden desplegarse mediante hipervínculos o vídeos, por ejemplo. Por otro lado, mecanismos ya utilizados en la prensa en papel se transforman para adaptarse al soporte pantalla, como el uso de la negrita. Pese a que algunos autores consideran que no hay pruebas de que la incorporación de contenidos multimedia a la prensa mejore el proceso comunicativo (Micó y Masip 2008), parece demostrarse que la incorporación de este tipo de contenidos en una noticia es percibida por los lectores como una innovación y su consumo resulta más satisfactorio (Canavilhas 2007). En el caso de informaciones especializadas, creemos que, junto con los mecanismos lingüísticos, las imágenes y los dispositivos visuales pueden constituir herramientas eficaces para divulgar conocimientos especializados.

\footnotetext{
${ }^{1}$ Este trabajo se enmarca en el proyecto de investigación Estrategias de textualidad del discurso profesional en soportes multimodales. Análisis y propuestas de mejora (FFI2011-28933), financiado por el Ministerio de Economía y Competitividad.
} 
El paso de la prensa escrita a la prensa digital ha supuesto la posibilidad de dotar a las piezas informativas de una mayor multimodalidad: diversos modos semióticos concurren en la construcción de un cierto significado. En el momento de "hipervisualidad" (Buxó 1999) que estamos viviendo, cabe reflexionar sobre el aspecto visual de los textos en la pantalla, aspecto que incluye no solo elementos como la fotografía, la infografía o el vídeo, sino también otros elementos considerados "paratextuales" que contribuyen igualmente en la creación del significado, como el cambio de color de la tinta para señalar elementos comunicativos dentro del discurso (Yúfera y otros 2013).

En este trabajo, centramos nuestra atención en la relación que se establece entre las imágenes y el texto de las noticias y crónicas de tema científico y jurídico de la prensa digital de nuestro país para analizar de qué manera esta combinación sinérgica contribuye en la construcción del significado global de estas piezas informativas.

\section{Objetivos}

Pese al incremento de la visualidad, y al notable interés que ha despertado entre los investigadores en comunicación desde perspectivas como la semiótica o la teoría de los medios, no se ha prestado una atención especial a las relaciones semánticas que se establecen entre imágenes y textos en los discursos digitales que nos interesan en este trabajo. La imagen trasciende a menudo la mera función de representación gráfica de contenidos presentes en el texto escrito, al menos si se entiende por "representar" mostrar de forma redundante lo que ya ha sido expresado, descrito o narrado con palabras en el texto.

Sin duda, esta función representativa aparece en las piezas informativas que hemos analizado, tanto en las de ciencia como en las de contenido jurídico. En estas últimas, por ejemplo, a menudo la imagen consiste en un retrato de un personaje relevante en la noticia y su función es "ponerle cara"2. Igualmente, sucede a menudo que la imagen que

\footnotetext{
${ }^{2}$ Poner cara a los nombres que aparecen en la noticia ayuda al público a identificar al personaje en cuestión y a humanizarlo. Siguiendo a Bednarek y Caple (2012), la imagen también puede desempeñar otras funciones comunicativas genéricas como evidenciar un hecho (la fotografía se presenta como un retrato fiel de la realidad que no "miente"); generar sentimientos en el lector/observador (especialmente en los medios de carácter sensacionalista, en que la imagen cobra mayor importancia que el texto y apela
} 
acompaña al texto de la pieza informativa no guarda una relación estrecha con este, en cuyo caso sencillamente rellena un hueco estructural en la pantalla sin una finalidad semántica concreta. Visto de esta forma, la imagen coaparece en el discurso como un elemento gráfico superfluo y no mantiene con el texto una relación de co-construcción del significado. Es decir, no hay una combinación intersemiótica que dota de coherencia al sentido global del texto, entendiendo este como la combinación de distintos modos semióticos que colaboran en la creación de un todo semántico y coherente que llamamos texto (o discurso) multimodal. En cualquier caso, creemos que es imprescindible analizar con mayor detalle y sistematicidad la relación que se establece entre las imágenes y el texto en los discursos que combinan distintos modos semióticos, como las noticias y crónicas en la prensa digital.

En este estudio queremos analizar cómo se establece la relación entre imagen y texto en la prensa digital de especialidad de los ámbitos jurídico y científico; y si esta relación contribuye eficazmente en la cohesión multimodal de estas piezas informativas en tanto que complejos semánticos de carácter multimodal. Nuestra hipótesis de partida es que especialmente en el ámbito científico, con una mayor tradición en el uso de estrategias de divulgación lingüístico-discursivas, habrá un uso más consistente de los modos visual y lingüístico, de manera que ambos coactuarán de forma coherente al servicio de la clarificación de los contenidos de especialidad. Para comprobar la validez de esta hipótesis, realizamos un análisis contrastivo entre ambos ámbitos informativos del mismo periódico. Asimismo, es importante señalar que el análisis intersemiótico que realizamos en este trabajo se limita a la metafunción ideacional (Halliday 1994) de ambos modos, esto es, la función relacionada con la transmisión de experiencias acerca del mundo (incluidos los mundos de nuestras mentes) y la descripción tanto de eventos y hechos como de las entidades involucradas en ellos (representación de la experiencia de objetos, procesos y circunstancias) ${ }^{3}$.

\footnotetext{
a los sentimientos del lector/observador); crear iconos (representar simbólicamente hechos clave en la historia (función icónica de la fotografía); transmitir sensaciones estéticas.

${ }^{3}$ Esta matización es pertitenente, ya que la relación entre el texto y la imagen puede trascender la simple representación de hechos y circunstancias para recrearlos mediante determinados efectos connotativos. De hecho, como hemos señalado en la nota 2, también puede transmitir sensaciones estéticas o generar en el lector/espectador determinados sentimientos y actitudes. Estos efectos de sentido que genera la imagen ya no se relacionan con la metafunción ideacional, sino con la interpersonal (Halliday 1994). Con esta función, el texto o la imagen se utilizan para interactuar con los demás, para establecer y mantener
} 


\section{Metodología}

Este trabajo se sitúa dentro del marco teórico del Análisis del discurso multimodal (Kress y van Leeuwen 2001) y del Análisis del discurso profesional. En consonancia con esta perspectiva, entendemos que los discursos son, por una parte, conocimiento socialmente construido sobre algún aspecto de la realidad; $y$, por otra, unidades comunicativas complejas de carácter multimodal.

Por socialmente construido entendemos que un discurso se desarrolla en un contexto social específico y adopta, en consecuencia, una forma apropiada a los intereses de los actores sociales en ese contexto. Así, desde la perspectiva de la semiótica social ${ }^{4}$ en que se enmarca nuestra investigación, concebimos la creación de significado como un fenómeno inherentemente social que centra la atención en los sistemas semióticos humanos, sus recursos, funciones, contextos y efectos (Hodge y Kress 1988). En el caso que nos ocupa, el de la prensa digital de contenido científico o jurídico, se trata de un contexto institucionalizado cuya función principal es la divulgación de conocimiento especializado.

Por su parte, la multimodalidad puede definirse como una perspectiva para el análisis discursivo (Jewitt 2009). En este sentido, el enfoque multimodal sostiene que las opciones de que dispone el usuario de una lengua en el proceso de comunicación no se limitan al plano del lenguaje verbal, sino que interactúan con otros sistemas semióticos en la creación del significado (Kress y van Leeuwen 1996, 2001). Los modos, por lo tanto, interactúan entre sí y hacen posible que un discurso sea analizado en función de sus estrategias para poder ser interpretado. Adoptar una perspectiva multimodal supone concebir la comunicación como un paisaje semiótico complejo en el que cada modo dentro del discurso aporta solo un significado parcial. Visto así, lo que antes habría de considerarse extralingüístico o residual por no expresarse de forma lingüística, como podría ser una imagen o un gráfico, ahora se coloca en el mismo nivel de análisis y

relaciones con ellas, para influir en su comportamiento y para expresar determinados puntos de vista sobre el mundo.

${ }^{4}$ En su desarrollo actual, la semiótica social persigue explicar cómo se crea significado mediante el uso de todos los recursos disponibles, tanto lingüísticos como de otro tipo: visuales, gestuales, musicales, coreográficos y accionales. De este modo, la semiótica social abre las puertas al estudio de cómo los diferentes grupos sociales crean significado mediante el recuso a todos los sistemas semióticos a su alcance. 
alcanza el mismo estatus que la expresión lingüística. Cada uno de los distintos sistemas semióticos que pueden concurrir en un discurso conlleva per se una carga o potencial de significado, que se corresponde con lo que cada modalidad semiótica es capaz de significar (Kress y van Leeuwen 2001, Kress y Mavers 2005). Esta perspectiva de análisis es especialmente relevante para abordar el estudio de textos que despliegan, de forma integrada, un uso creciente de diversos elementos visuales y lenguaje verbal en la creación del significado textual. Para su análisis, el acercamiento logocéntrico basado en la primacía del lenguaje verbal sobre otros modos semióticos resulta claramente insuficiente.

Este trabajo forma parte de una investigación más amplia centrada en el análisis multimodal del discurso digital de especialidad. En él queremos mostrar que la aplicación de una perspectiva multimodal al análisis de este tipo de discursos contribuye sustancialmente a su descripción teórica y a la comprensión de cómo se crea y cómo se transmite el conocimiento especializado a través de los medios digitales. Para ello, hemos realizado un análisis contrastivo de carácter descriptivo a partir de un corpus compuesto por 15 piezas de tema científico y 15 de tema jurídico de la edición digital del diario $A B C$. Se trata de noticias y crónicas publicadas entre 2010 y 2012, extraídas de un corpus mayor, compuesto de piezas informativas de 6 de los principales periódicos españoles con edición digital: $A B C$, El País, El Mundo, Público, El Periódico y La Vanguardia.

El análisis de la relación entre los aspectos visuales y lingüísticos que aplicamos en este trabajo se apoya en el modelo intersemiótico propuesto por Martinec y Salway (2005) para el análisis de las relaciones entre texto e imagen en diferentes géneros de discurso multimodal. Este modelo combina, por un lado, las relaciones lógico-semánticas y de estatus planteadas por Halliday $(1985,1994)$ para las relaciones entre cláusulas en la oración compleja, y, por otro, las relaciones entre imagen y texto propuestas por Barthes ([1961] 1997a, [1964] 1997b).

Halliday establece una diferenciación entre el tipo de relaciones que pueden mantener entre sí dos cláusulas, según sean estas sintácticas o lógico-semánticas. En cuanto a la relación sintáctica, esta puede ser de igualdad cuando ambas cláusulas poseen el mismo estatus sintáctico (relación paratáctica); o bien de desigualdad, si no poseen el mismo 
estatus sintáctico (relación hipotáctica). Respecto de las relaciones lógico-semánticas, estas representan la manera como el hablante percibe la conexión semántica entre las cláusulas. Las relaciones lógico-semánticas pueden ser de expansión, cuando la cláusula secundaria expande la primaria mediante elaboración, extensión o ampliación (Halliday 1994) $)^{5}$ o de proyección, cuando la cláusula secundaria se proyecta a través de la primaria, bien como una locución mediante verbos dicendi (dice que, opina que...), bien como una idea, mediante verbos de pensamiento (cree que, piensa que...). Las relaciones lógico-semánticas de Halliday presentan un nivel de abstracción que permite su aplicación al análisis de las relaciones que se establecen entre otras unidades del discurso, como las imágenes y el texto, tal como demuestran los trabajos de van Leeuwen (1991) o Martinec y Salway (2005).

A las relaciones hallidayanas de estatus de igualdad o independencia y desigualdad o dependencia entre cláusulas, Martinec y Salway añaden un tercer tipo de relación que toman de Barthes, el de complementariedad, para dar cuenta de la relación de interdependencia que se establece entre una imagen y el texto cuando estas son mutuamente dependientes. De este modo, el estatus de igualdad de Halliday se divide en dos subtipos: estatus independiente y estatus complementario (Martinec y Salway 2005: 343).

\section{Análisis}

4.1. El modo icónico. Las palabras y los dispositivos visuales

El conocimiento jurídico y el conocimiento científico presentan diferentes grados de visibilización (Yúfera 2013). Las características de la información científica la hacen más visualizable que las de la información jurídica, lo cual podría corresponderse a una

\footnotetext{
${ }^{5}$ La elaboración semántica de una cláusula consiste en una especificación o descripción más detallada de esta mediante otra cláusula en aposición (parataxis) o en forma de relativa explicativa (hipotaxis). Con la elaboración, la cláusula secundaria no introducen elementos nuevos en el discurso, sino que aporta una caracterización más amplia de un elemento presente en la cláusula primaria. Por su parte, la extensión supone una extensión de la cláusula primaria añadiendo más información (adición), sustituyéndola (variación), presentando alternativas (alternancia), comentándola o explicándola (explicación) o mostrando excepciones o salvedades (excepción) (González 2003). Por último, la ampliación amplía semánticamente la cláusula primaria mediante significados circunstanciales temporales, locativos, condicionales, causal-consecutivos, concesivos, etc.
} 
mayor presencia de imágenes y dispositivos visuales en las piezas informativas de contenido científico que en las de contenido jurídico. Sin embargo, en este momento de nuestra cultura, las imágenes que acompañan a los textos han adquirido una gran relevancia por su fuerza persuasiva en textos de cualquier ámbito del conocimiento.

Como sostiene Vega (2012: 45), "los conceptos científicos mismos no son únicamente verbales, sino que se estructuran como «híbridos semióticos», simultáneamente verbales, matemáticos, visuales y operacionales”. En el caso del conocimiento jurídico, en cambio, no son las imágenes sino las palabras lo que ocupa un lugar central en su desarrollo y en su transmisión: el de los juristas es un quehacer eminentemente discursivo, pues consiste fundamentalmente en leer y redactar textos legales. De ahí que las noticias relacionadas con cuestiones de legislación o de tribunales primen también la información verbal sobre la visual. Lo que cuentan los periodistas tiene que ver, fundamentalmente, con eventos lingüísticos que han tenido lugar en un juicio o con decisiones que han sido redactadas en forma de texto jurídico (edicto, sentencia, norma, (proyecto de) ley, etc.). La imagen que acompañe al texto de estas noticias puede guardar distintas relaciones con este, pero, a diferencia de las noticias sobre ciencia, raramente constituyen por sí mismas un hecho noticiable.

\subsection{Análisis intersemiótico de la relación imagen-texto}

Como hemos apuntado en el apartado 3, el modelo de análisis intersemiótico de Martinec y Salway se compone de dos subsistemas que se combinan de forma independiente: (i) el sistema de relación de estatus que mantienen entre sí la imagen y el texto dentro del discurso en tanto que elementos semióticos (igualdad: independencia, complementariedad, o desigualdad: subordinación) (ver Tabla 1); y (ii) el sistema de relaciones lógico-semánticas que cohesiona y dota de coherencia a dicha relación: expansión y proyección (ver Tabla 2).

Igual que las cláusulas de un complejo de cláusulas, una imagen y un texto mantendrán una relación de igualdad cuando la imagen completa se relaciona con el texto completo $^{6}$. Normalmente, la imagen refleja un proceso o una combinación de procesos.

\footnotetext{
${ }^{6}$ Por texto, en este trabajo entendemos cualquier unidad comunicativa completa, del rango que sea, que mantenga una relación de estatus o lógico-semántica con la imagen en cuestión. Por lo general, el rango
} 
En estos casos, la relación puede ser de independencia si ambos recursos semióticos aportan la información en paralelo, de modo que cada modo constituye su propio proceso; o de interdependencia, cuando se combinan para aportar el sentido completo de la información. En cambio, la relación entre imagen y texto es de desigualdad o subordinación cuando unos de estos elementos modifica al otro, es decir, cuando uno de ellos se relaciona con el otro solo de forma parcial: la imagen refiere a una parte del texto o viceversa.

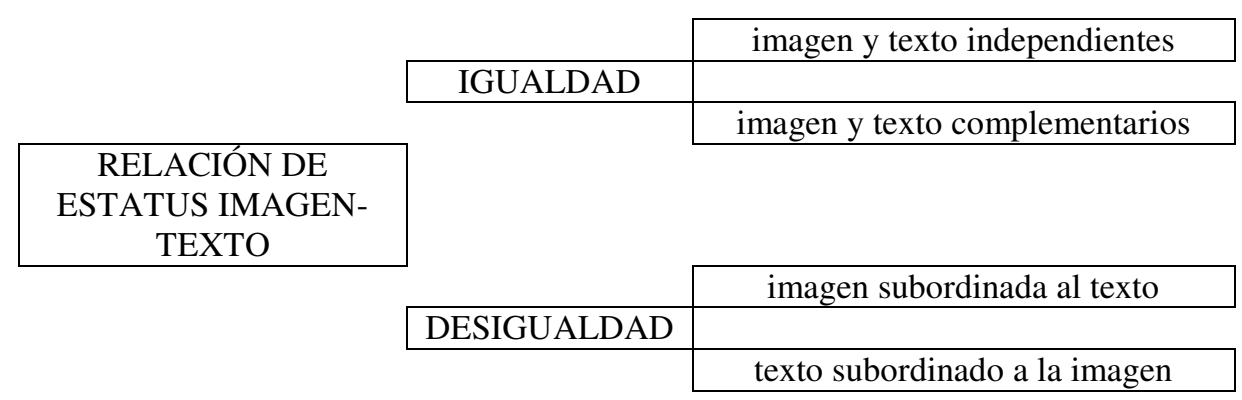

Tabla 1: Relaciones de estatus entre imagen y texto ${ }^{7}$

Además del estatus que mantienen entre sí la imagen y el texto, para dotar de cohesión semántica a la relación texto-imagen es necesario identificar las relaciones de sentido que se establecen entre los dos tipos de elemento semióticos. Esta relación, como ya hemos apuntado anteriormente, puede ser de expansión o de proyección (ver tabla 2).

La relación de expansión supone siempre una ampliación del significado de uno de los elementos por el otro. Esta expansión puede realizarse mediante la elaboración del contenido de uno de los elementos, especificando o describiéndolo de forma más detallada (exposición) o aportando un ejemplo (ejemplificación). Cuando la relación es expositiva, el texto y la imagen poseen el mismo nivel de generalidad y no se introducen elementos significativos nuevos en el discurso, sino que se aporta una caracterización más amplia de un elemento ya presente en el texto o en la imagen. En cambio, si la relación es de ejemplificación, el grado de generalidad variará según cuál sea el

de la unidad textual que se relaciona con la imagen suele ser el párrafo o una unidad inferior, como la cláusula o el complejo de cláusulas. No obstante, la unidad textual puede ser superior al párrafo cuando la relación imagen-texto se refiere al tópico discursivo de la pieza informativa; o, en algunos casos, el rango puede ser inferior a la cláusula, por ejemplo un grupo nominal o una palabra, generalmente sustantivos o adjetivos. En cualquier caso, entendemos que la relación intersemiótica se establece entre procesos que interactúan lingüística y visualmente -esto es, que se expresan en los dos modos al mismo tiempo-, o entre los participantes o circunstancias de dicho proceso.

${ }^{7}$ Este esquema está adaptado de Martinet y Salway (2005: 349). 
elemento que ejerza la función ejemplificadora: si es la imagen, el texto es más general; si es el texto, lo es la imagen. Por su parte, la extensión del contenido del texto o la imagen se consigue añadiendo más información (adición), sustituyéndola (variación), presentando alternativas (alternancia), comentándola o explicándola (explicación) o mostrando excepciones o salvedades (excepción). Por último, la ampliación amplía semánticamente la cláusula primaria mediante significados circunstanciales temporales, locativos, condicionales, causal-consecutivos, concesivos, etc.

La relación de proyección resulta de especial interés para dar cuenta de los vínculos que se establecen en algunas piezas informativas entre un esquema o un diagrama y el correspondiente texto que los explica. En estos casos, la proyección del significado se produce entre la explicación del texto y la idea que refleja la imagen, que reproduce gráficamente (esto es, simbólicamente) el contenido conceptual del texto. Resulta igualmente rentable para explicar la relación que se establece en algunas noticias entre el texto que reproduce directamente las palabras de algún personaje relevante de la noticia (en el cuerpo de la noticia) y una imagen que representa un proceso verbal (imagen del personaje hablando, que conduce a menudo a un documento audiovisual).

\begin{tabular}{|c|c|c|c|}
\hline \multicolumn{4}{|c|}{ Expansion } \\
\hline \multirow{2}{*}{\multicolumn{2}{|c|}{$\begin{array}{c}\text { elaboración } \\
\text { (no se añade más información) }\end{array}$}} & extensión & ampliación \\
\hline & & (se añade más información) & (se añade más información) \\
\hline exposición & ejemplificación & $\begin{array}{l}\text { adición, variación, alternancia, } \\
\text { explicación, excepción }\end{array}$ & $\begin{array}{c}\text { tiempo, lugar, causa-consecuencia, } \\
\text { finalidad }\end{array}$ \\
\hline \multirow{2}{*}{\multicolumn{2}{|c|}{$\begin{array}{l}\text { imagen y texto } \\
\text { misma } \\
\text { generalidad }\end{array}$}} & & \\
\hline & & \multirow[t]{2}{*}{ Proyección } & \\
\hline \multicolumn{2}{|r|}{ locución } & & idea \\
\hline \multicolumn{2}{|c|}{ reproducir discurso ajeno } & & representar conceptos \\
\hline
\end{tabular}

Tabla 2: Relaciones lógico-semánticas entre imagen y texto

En el siguiente apartado exponemos, con finalidad exploratoria, algunos de los ejemplos de combinación intersemiótica entre imagen y texto que hemos encontrado en el corpus analizado. La exposición se presenta mediante el análisis combinado de la relación de estatus y lógico-semántica de cada caso. 
4.3. Relaciones entre imagen y texto. Combinación de estatus y semántica

\subsubsection{Estatus de igualdad}

\subsubsection{Imagen y texto independientes, exposición}

Un ejemplo de independencia entre imagen y texto puede verse en la figura 1. En este caso, el elemento relevante en la noticia es la imagen en sí misma, que muestra un mapa del universo a la edad de 380.000 años.

\section{La imagen más detallada de los restos del Big Bang}

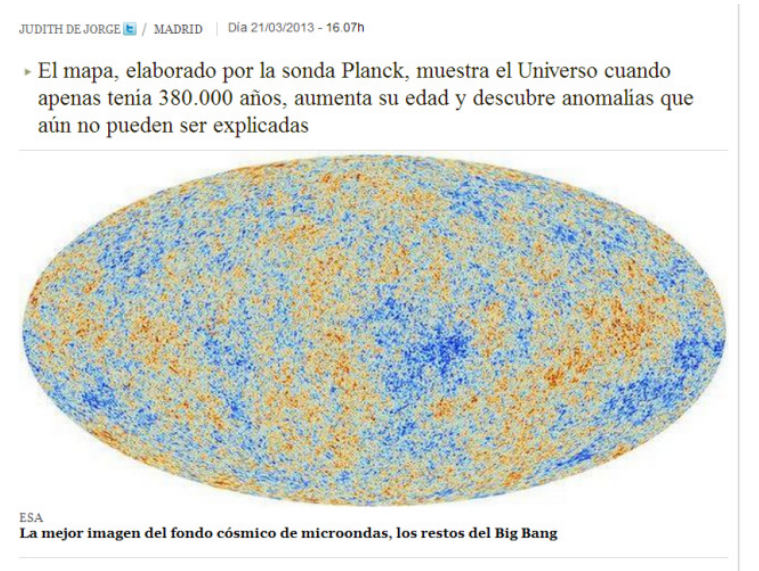

Figura 1: $A B C$, ciencia, La imagen más detallada...

Tanto el texto del párrafo que acompaña a la imagen en la parte superior, como el texto del pie de la imagen informan sobre qué representa la imagen, y lo hacen mediante una claúsula que expresa un proceso relacional de identificación (Halliday 1994: 122-8). En el párrafo, el grupo nominal el mapa representa el papel de elemento identificado y el grupo nominal el universo representa al elemento identificador; el verbo ser expresa el proceso. Asimismo, en el pie de imagen hay un elemento identificador (los restos del Big Bang) y un elemento identificado (La mejor imagen del fondo cósmico de microondas"); la coma sustituye al proceso mismo, que está implícito. Por su parte, la imagen es un proceso atributivo simbólico (Kress y Van Leeuwen 1996: 108), en el que el mapa representa el papel de portador, y las partes coloreadas el atributo. Ambos elementos semióticos expresan un proceso completo de forma independiente, pero en

\footnotetext{
${ }^{8}$ http://www.abc.es/ciencia/20130321/abci-imagen-detallada-restos-bang-201303211258.html
} 
paralelo, de modo que la imagen completa (esto es, el proceso que representa visualmente) se relaciona con el texto completo (es decir, con el proceso expresado lingüísticamente en las cláusulas atributivas del párrafo y el pie de imagen).

La relación lógico-semántica entre la imagen y el texto es de elaboración por exposición: ambos elementos semióticos presentan el mismo nivel de generalidad y aportan el mismo contenido mediante modos semióticos diferentes. De hecho, la relación puede entenderse como una reformulación parafrástica apositiva ( $\sin$ nexo explícito) en la que el contenido simbólico de la imagen expone el contenido ideacional del texto -o viceversa, según dónde se quiera poner el énfasis.

\subsubsection{Imagen y texto independientes, ejemplificación (texto más general)}

El siguiente ejemplo (Figura 2) muestra también una relación de igualdad entre la imagen y el texto. Se trata de una noticia que pertenece a la sección de Tribunales; el hecho noticiado es el aumento de robos en el campo aragonés y la exigencia de los agricultores de aumentar la vigilancia policial en el campo.

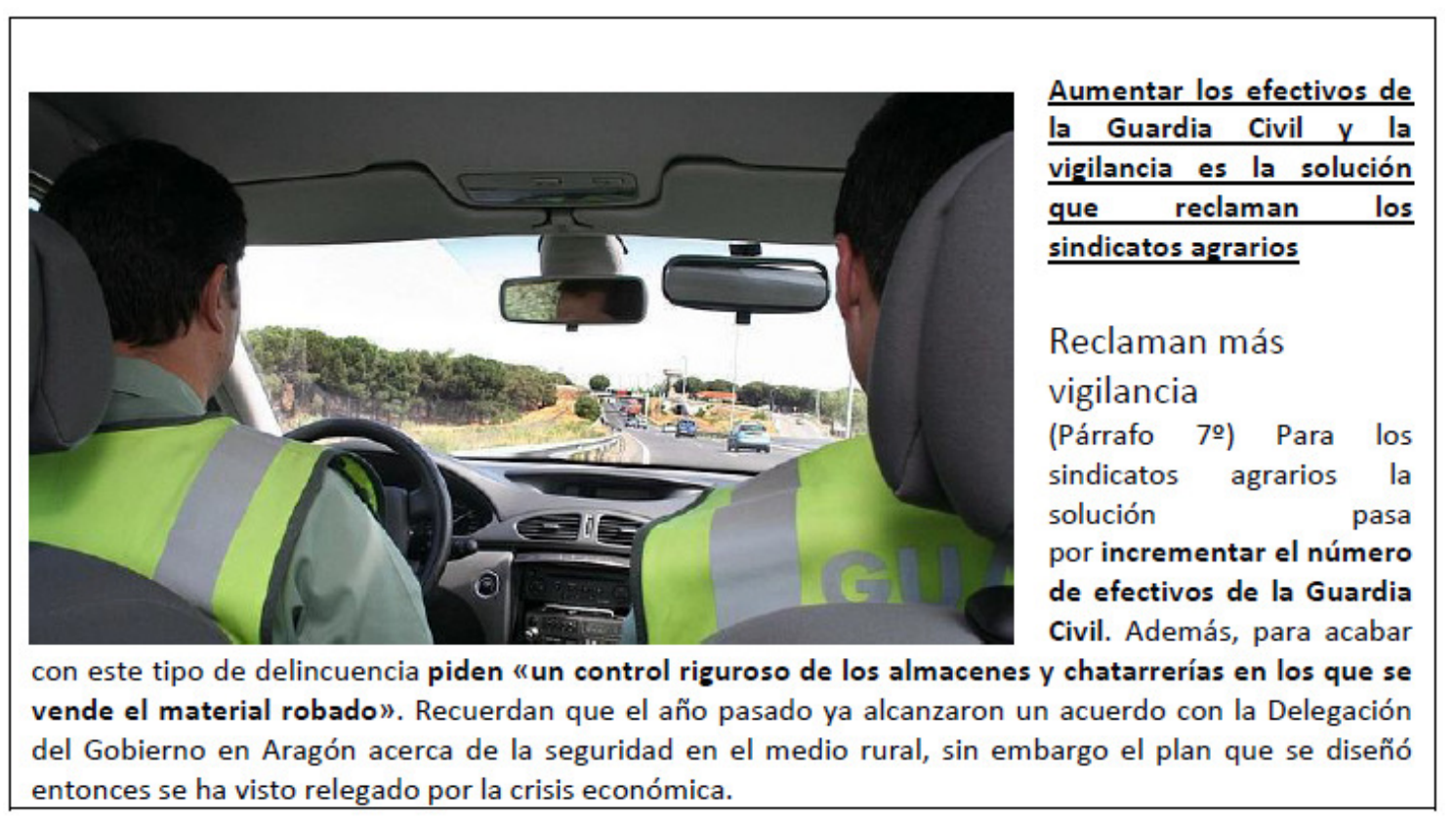

Figura 2: ABC, tribunales, El campo aragonés... ${ }^{9}$

La imagen está relacionada con dos textos distintos: con el pie de foto (Aumentar los efectivos de la Guardia Civil y la vigilancia es la solución que reclaman los sindicatos

\footnotetext{
${ }^{9}$ http://www.abc.es/local-aragon/20130325/abci-campo-aragon-sufrio-6000-201303250949.html
} 
agrarios); y, en el párrafo séptimo, en el que se aborda la información sobre la reclamación de los agricultores, con la primera cláusula (Para los sindicatos agrarios la solución pasa por incrementar el número de efectivos de la Guardia Civil). Ambos textos, igual que en el ejemplo de la figura 1, están formados por sendas cláusulas que expresan un proceso atributivo de identificación. Por su parte, la imagen muestra a una pareja de guardias civiles conduciendo por la carretera. En principio, esta acción se interpreta como una de las funciones principales de este cuerpo de seguridad: patrullar, y más concretamente, patrullar para vigilar. Por ello, la imagen puede interpretarse como un proceso material intransitivo ('alguien hace'), en el que los guardias civiles actúan como agentes de la acción y el proceso se representa implícitamente con la imagen de los agentes patrullando por las carreteras. En definitiva, la relación de la imagen con los textos es de independencia, ya que cada elemento semiótico transmite un proceso completo por sí mismo, esto es, aporta información en paralelo.

La relación lógico-semántica que se establece entre imagen y texto es de elaboración mediante ejemplificación: las patrullas de la Guardia Civil representan un ejemplo de lo que los sindicatos agrarios entienden como solución a su problema. La relación es de hiponimia: el texto es más general y funciona como elemento superordinado (aumentar los efectivos de la GC, aumentar la vigilancia en el campo); la imagen, por su parte, representa el elemento subordinado, más concreto (las patrullas por carretera). Esta relación podría parafrasearse como "la solución es incrementar el número de efectivos de la GC [proceso textual], por ejemplo [relación lógico-semántica implícita], guardias civiles patrullando por las carreteras [imagen]".

\subsubsection{Estatus de desigualdad}

\subsubsection{Texto subordinado a la imagen, ampliación}

Una de las realizaciones más frecuentes de texto subordinado a la imagen es la que se produce cuando el texto contiene elementos anafóricos que tienen que interpretarse por referencia a la imagen. Se trata generalmente de datos que describen no solo el contenido visualizable de la imagen, sino también aspectos relacionados con el personaje, el objeto o el lugar representado. Este tipo de información amplía el contenido de la imagen y depende de ella para ser contextualizado. 
La figura 3 ilustra lo que acabamos de explicar. El texto de esta noticia trata sobre el descubrimiento de las llamadas "buckybolas".

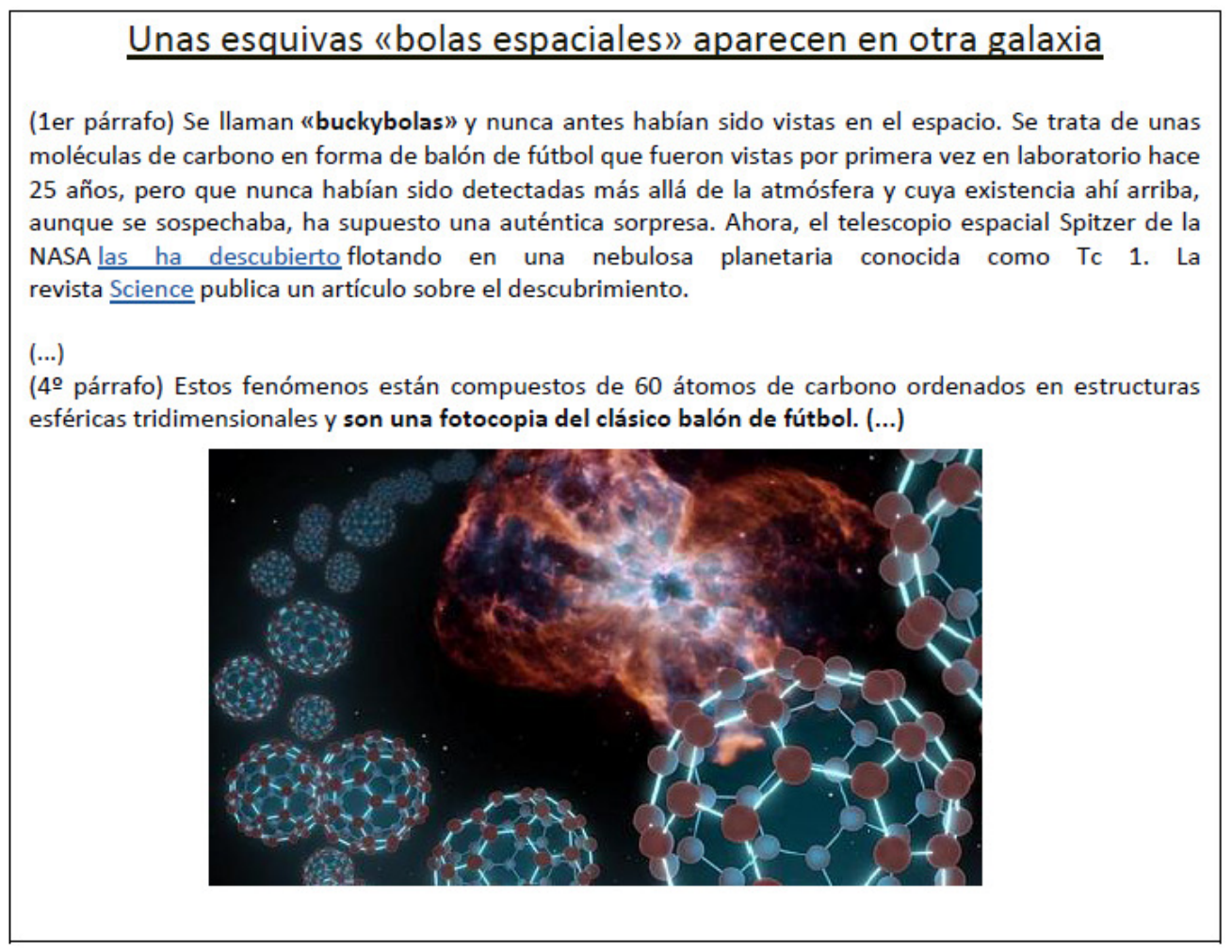

Figura 3: ABC, ciencia, Unas esquivas «bolas espaciales» ${ }^{10}$

Tanto el titular como el cuerpo de la noticia se relacionan con la imagen por medio de referencias que señalan al objeto representado. El titular se realiza mediante una cláusula relacional atributiva en la que el papel de portador se expresa con el término metafórico bolas espaciales. Este elemento se relaciona por sinonimia con la forma esférica de los objetos representados en la imagen, que tienen el mismo papel dentro del proceso atributivo simbólico de la imagen (atributo). En el cuerpo de la noticia, la alusión a la imagen se realiza a través del mismo elemento mencionado en el titular, que constituye el tópico de la noticia, pero su realización en las cláusulas de los párrafos utiliza elementos referenciales: elisión, pronombre anafórico (las ha descubierto) y anáfora léxica (estos fenómenos). El texto no solo describe qué son (moléculas de carbono), cómo son (esféricas, en forma de balón de fútbol) y cómo se llaman (buckybolas) los objetos representados en la imagen (información básica, en relación de exposición con la imagen), sino que también amplía la información con datos sobre el

\footnotetext{
${ }^{10}$ http://www.abc.es/20100723/ciencia/descubren-unas-bolas-espaciales-201007231741.html
} 
cuándo, el dónde y el cómo del descubrimiento del objeto (información de carácter circunstancial). En definitiva, por un lado, la información del texto expone lo que ve el lector en la imagen (relación expositiva); por otro, amplía el conocimiento del lector sobre el objeto representado (relación de ampliación).

\subsubsection{Texto subordinado a la imagen, exposición}

La subordinación del texto a la imagen también aparece con frecuencia en los pies de foto (Martinec y Salway 2005: 347). Se trata generalmente de la combinación de procesos materiales (alguien hace algo) o de comportamiento (alguien se comporta de determinada manera) expresados en presente o presente continuo. Pese a que estos casos inducen a pensar que el texto y la imagen son independientes y que cada uno de ellos expresa el mismo proceso en paralelo, la imagen tiene mayor peso informativo y el proceso expresado en la cláusula describe lo que está sucediendo en la imagen.

La figura 4 muestra este tipo de relación. El pie de foto y la imagen expresan el mismo contenido y el texto describe el proceso de comportamiento representado.

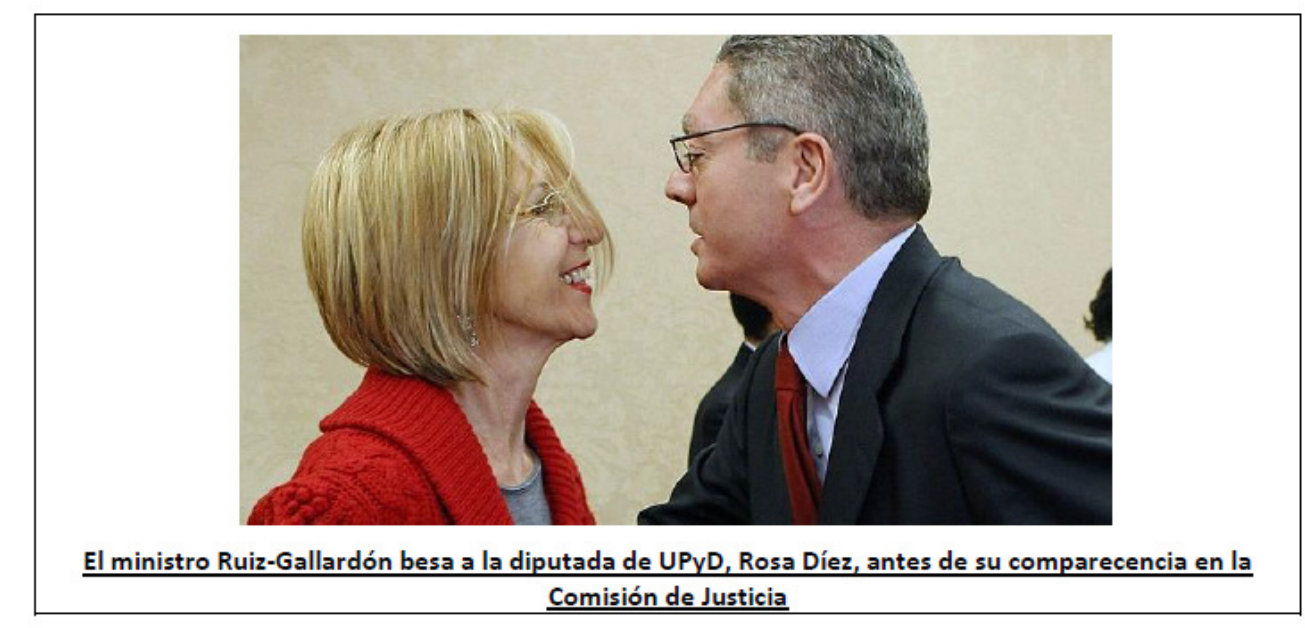

Figura 4: ABC, tribunales, El ejecutivo se plantea la prisión permanente revisable ${ }^{11}$

\subsubsection{Imagen subordinada al texto, exposición, ampliación}

A diferencia de lo que ocurre con los procesos materiales y de comportamiento expresados en presente, los tiempos de pasado subordinan la imagen al texto. Martinec y Salway (2005:348) explican este funcionamiento del pasado a partir de la

\footnotetext{
${ }^{11}$ http://www.abc.es/20120125/espana/abci-gallardon-prision-permanente-201201251140.html
} 
conceptualización que propone Halliday (1994) de los tiempos verbales como elementos deícticos. Según estos autores, al situar los tiempos verbales en el mismo nivel semántico que los elementos referenciales (que suponen un tipo de deixis), aquellos permiten relacionar el texto y la imagen. Así, los tiempos de presente pueden interpretarse como marcas que señalan a la acción que se está desarrollando en la imagen, subordinando el texto a la imagen. En cambio, los tiempos de pasado apuntan más allá de la imagen, ya que expresan una acción que trasciende lo que se representa en ella; esto impide que se interprete el texto como subordinado a la imagen.

Un ejemplo de lo que acabamos de exponer puede verse en la relación que mantiene el texto (titular, subtítulo y cuerpo de la noticia) de la siguiente noticia (figura 5) sobre el descubrimiento de una momia y la imagen de la dentadura.

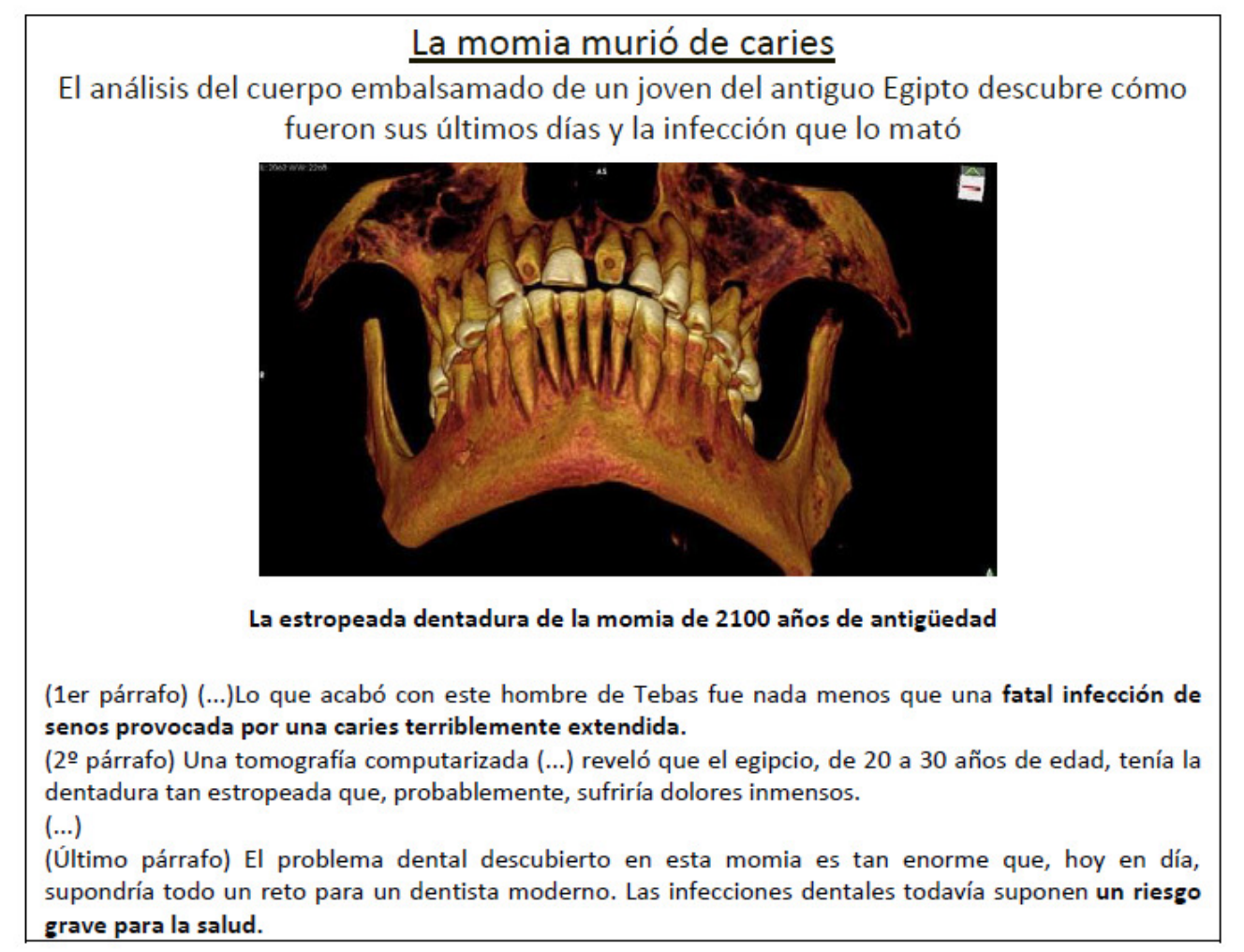

Figura 5: ABC, ciencia, La momia murió de caries ${ }^{12}$

La relación lógico-semántica entre estos textos y la imagen es de dos tipos: expositiva y de ampliación. La exposición se realiza a través de la identificación entre la dentadura del joven egipcio y la infección que sufría y la imagen que muestra la dentadura y el estado de esta; ninguno de los modos semióticos añade información respecto del otro.

\footnotetext{
${ }^{12}$ http://www.abc.es/20121011/ciencia/abci-momia-murio-caries-201210111511.html
} 
La ampliación, por su parte, viene dada por dos informaciones del texto que refieren a la causa de la infección y a las consecuencias de esta: una caries provocó la infección y la muerte; la infección tan severa tiene como consecuencia su imposibilidad de tratamiento en la época referida por la noticia. La tabla 3 muestra con mayor detalle estas relaciones entre la imagen y el texto de la noticia.

texto El análisis del cuerpo embalsamado de un joven del antiguo Egipto descubre la infección que lo (Subtítulo) mató. (El elemento marcado en negrita representa la meta del proceso material expresado por la
cláusula)

$\begin{array}{cl}\text { imagen } & \begin{array}{l}\text { Estado de la dentadura correspondiente a una infección severa. (El estado de la dentadura se } \\ \text { corresponde con el elemento identificador del proceso atributivo simbólico que representa la } \\ \text { imagen) (La imagen no añade información) }\end{array} \\ \text { texto } & \begin{array}{l}\text { Lo que acabó con este hombre de Tebas fue nada menos que una fatal infección de senos } \\ \text { provocada por una caries terriblemente extendida. (El elemento marcado en negrita expresa el } \\ \text { actor metafórico del proceso material expresado por la cláusula; el marcado en cursiva, } \\ \text { información circunstancial sobre la causa de la infección) }\end{array} \\ \text { imagen } & \begin{array}{l}\text { Estado de la dentadura correspondiente a una infección severa. (El estado de la dentadura se } \\ \text { corresponde con el elemento identificador del proceso atributivo simbólico que representa la } \\ \text { imagen; la imagen representa la infección) (La imagen no añade información) }\end{array} \\ \text { texto } & \begin{array}{l}\text { Una tomografía computarizada (...) reveló que el egipcio, de 20 a 30 años de edad, tenía la } \\ \text { dentadura tan estropeada que, probablemente, sufriría dolores inmensos. (El elemento en } \\ \text { negrita expresa el atributo del proceso atributivo posesivo de la cláusula en que aparece) }\end{array} \\ \text { imagen } & \text { Estado de la dentadura. (La imagen no añade información) } \\ \text { texto } & \begin{array}{l}\text { El problema dental descubierto en esta momia es tan enorme que, hoy en día, supondría } \\ \text { todo un reto para un dentista moderno. (La cláusula expresa un proceso atributivo; el elemento } \\ \text { en cursiva expresa un dato circunstancial sobre la consecuencia médica del estado de la } \\ \text { dentadura; este dato amplía la información sobre la imagen y está supeditada a esta para } \\ \text { contextualizar el alcance del estado y la consecuencia expresada en el texto) }\end{array} \\ \text { (último párr.) } & \begin{array}{l}\text { La dentadura muestra el problema de deterioro provocado por la infección (la imagen representa } \\ \text { el proceso atributivo completo; como proceso global, la imagen no añade información) }\end{array} \\ & \end{array}$

Tabla 3: Relación lógico-semántica entre imagen y texto en la noticia La momia murió de caries

\subsubsection{Imagen subordinada al texto, ejemplificación y extensión}

Como hemos apuntado antes, cuando una imagen se subordina al texto, aquella se relaciona solo parcialmente con este. Así ocurre en el siguiente ejemplo (Figura 6), en el que la imagen de una de las especies más raras descubiertas en el año 2010, una sanguijuela, no se relaciona con toda la información que trata sobre el animal (el 
subtítulo y el cuerpo del texto), sino que solo lo hace con una parte del texto contenida en el cuerpo de la noticia que especifica algunas de sus características ${ }^{13}$.

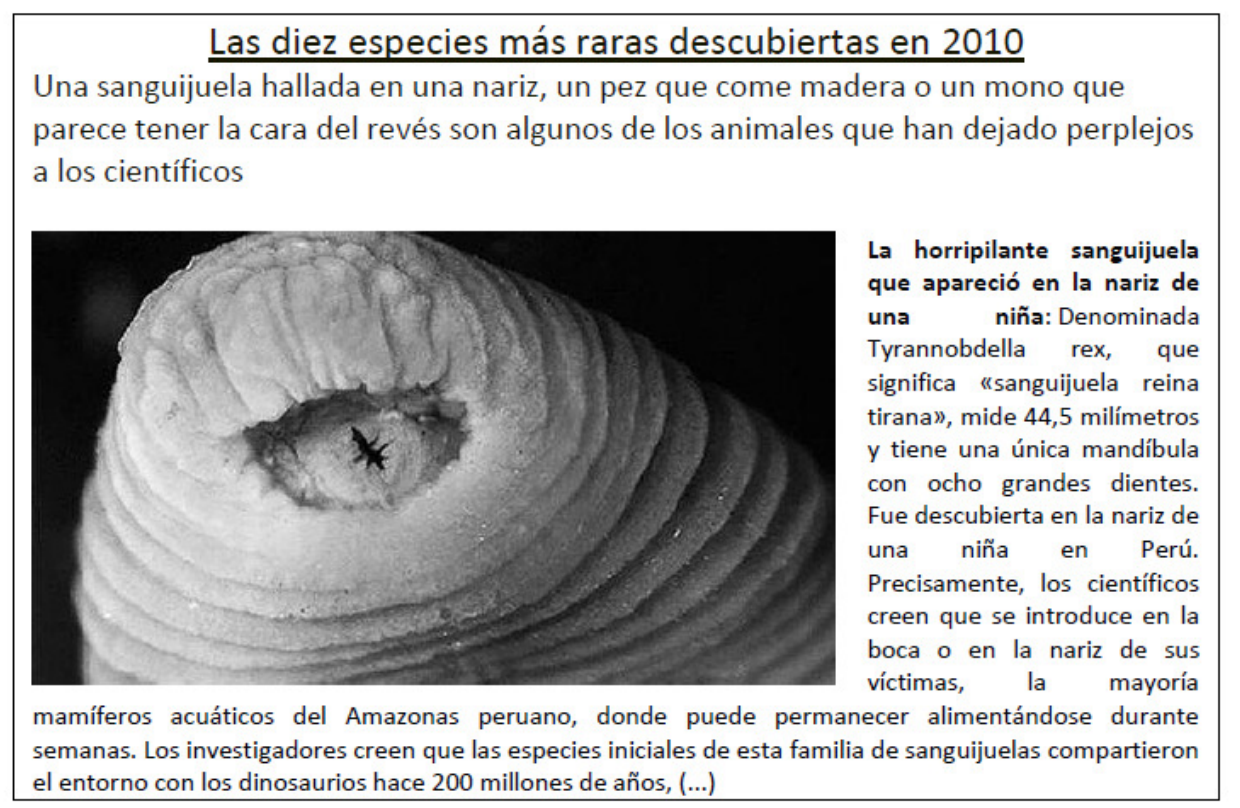

Figura 6: ABC, ciencia, Las diez especies más raras ${ }^{14}$

De los atributos que se mencionan en el cuerpo de la noticia: el tamaño y la descripción de la mandíbula, en la imagen solo puede apreciarse el segundo de ellos. Sin embargo, este mismo texto menciona también otros datos relacionados con el animal que amplían el contenido de la imagen: el tamaño del animal, el lugar donde ha sido descubierto y la manera de proceder del animal. La imagen, pues, no es independiente respecto del texto del cuerpo de la noticia y mantiene con él una relación semántica de dos tipos.

Por un lado, la imagen se subordina al texto al ejemplificar el atributo del proceso relacional descrito en la cláusula atributiva posesiva La horripilante sanguijuela [...] tiene una única mandíbula con ocho grandes dientes. La imagen muestra la boca del animal, que contiene la mandíbula.

Por otro lado, la subordinación de la imagen se realiza respecto de otras partes del texto que amplían el contenido de la imagen. Una de ellas es la cláusula atributiva intensiva

\footnotetext{
${ }^{13}$ Cabe comentar que la imagen también mantiene una relación de estatus independiente con el texto del subtítulo. Ambos elementos semióticos representan un proceso relacional identificativo completo (X es Y) que informa en paralelo del mismo contenido. La imagen completa representa el proceso relacional del texto y la sanguijuela cumple el papel de identificador. La relación semántica entre la imagen y el texto es de exposición.

${ }^{14}$ http://www.abc.es/20101215/ciencia/diez-especies-raras-descubiertas-201012150948.html
} 
La horripilante sanguijuela mide 44,5 milímetros, en la que se describe otro atributo del animal que no puede observarse en la imagen: el tamaño. Asimismo, en el texto aparecen dos informaciones que aluden al modus operandi del animal y a su origen. Se trata de las cláusulas se introduce en la boca o en la nariz de sus víctimas, la mayoría mamíferos acuáticos del Amazonas peruano, donde puede permanecer alimentándose durante semanas y las especies iniciales de esta familia de sanguijuelas compartieron el entorno con los dinosaurios hace 200 millones de años, respectivamente. El anclaje entre el texto y la imagen se establece mediante mecanismos de cohesión: elisión y repetición, que unen a los actores de los procesos materiales descritos en ambas cláusulas (el sujeto elidido en la primera cláusula y el grupo nominal sujeto en la segunda)

\subsubsection{Imagen subordinada al texto, proyección de ideas}

La figura 7 muestra un ejemplo de relación subordinada entre la imagen de la izquierda (representación de las órbitas de la tierra y el asteroide) y el texto de la noticia ${ }^{15}$. El texto proporciona todo el contenido semántico de la imagen de la izquierda, ya que describe detalladamente el significado de la imagen, que debe interpretarse por remisión al texto.

En cuanto a la relación lógico-semántica entre el texto y la imagen, puede considerarse, siguiendo el modelo de Martinec y Salway (2005: 352-354), de proyección de ideas. Según estos autores, la combinación de texto con diagramas y dibujos naturalistas que representan conceptos y se acompañan de etiquetas identificativas del objeto o sus partes representa un caso de proyección. En el caso que nos ocupa, la imagen representa un diagrama de las órbitas que describe la tierra y el asteroide del que se da noticia; además de la imagen gráfica, aparecen también etiquetas identificativas, que podrían considerarse texto. Estas etiquetas, sin embargo, no aportan el contenido semántico

\footnotetext{
${ }^{15} \mathrm{La}$ imagen de la derecha representa una captación del asteroide, que se relaciona con la primera cláusula del párrafo: [...], un grupo de astrónomos [...] descubrió un asteroide [...]. La relación de estatus entre esta imagen y el texto es de independencia y la relación semántica es de exposición. El texto expresa un proceso material (descubrir) cuya meta (el objeto sobre el que recae la acción) es el asteroide. La imagen, por su parte, representa bien un proceso intensivo identificativo simbólico, en el que la imagen completa es el identificador, el punto dentro del círculo es el identificado y el proceso está implícito en el círculo que engloba el asteroide; o bien representa el proceso material de "descubrir" el asteroide: la imagen representa el proceso del descubrimiento y el círculo la meta del descubrimiento.
} 
(ideacional) de la imagen, sino que es el texto de la noticia el que lo expresa lingüísticamente. Por ello, tanto la imagen como las etiquetas se consideran imagen ${ }^{16}$. En estos casos, la proyección del significado se produce entre la explicación del texto y la idea que refleja la imagen, que reproduce gráficamente (esto es, simbólicamente) el contenido conceptual del texto.

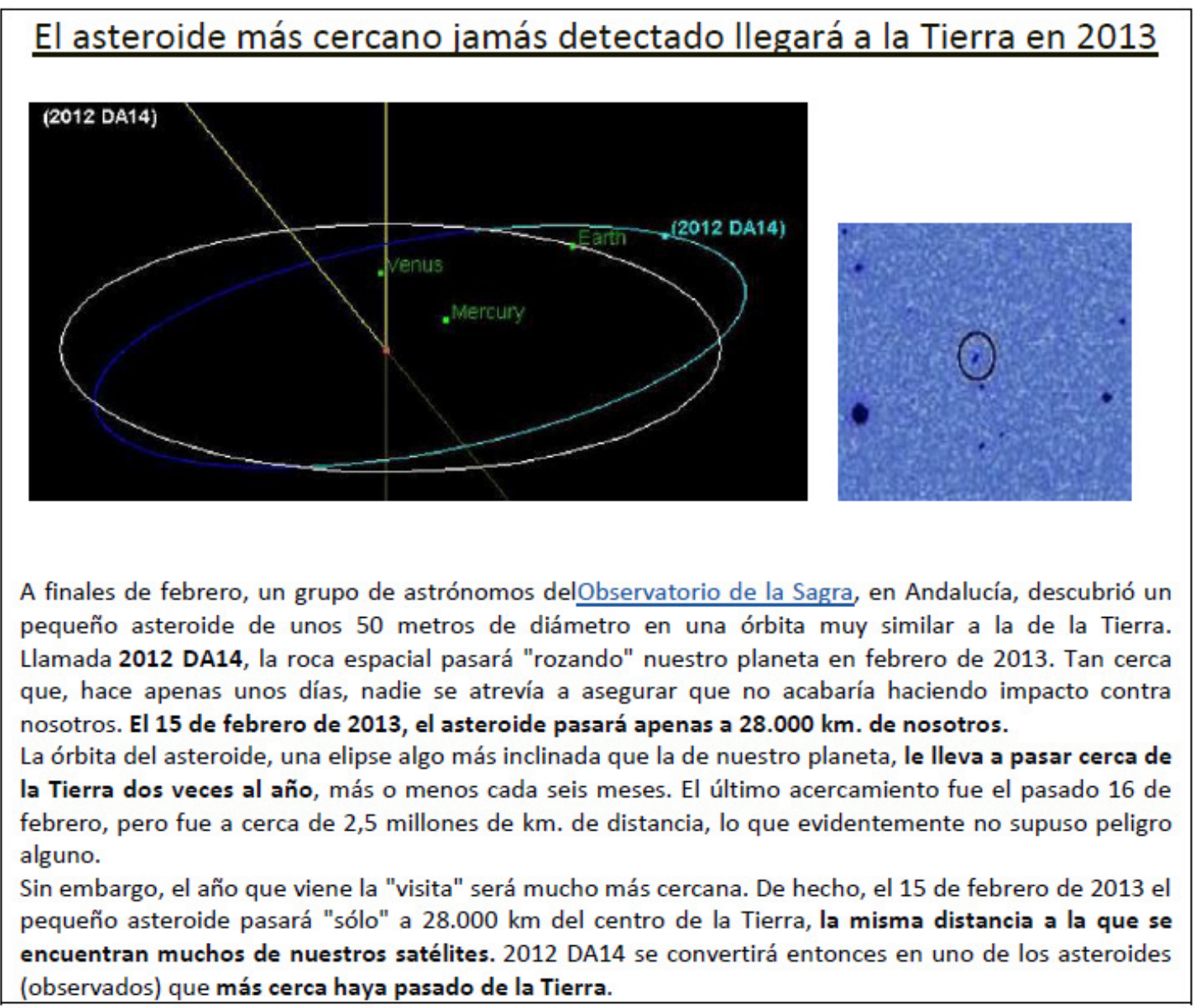

Figura 7: ABC, ciencia, El asteroide más cercano ${ }^{17}$

\footnotetext{
${ }^{16}$ Estos autores consideran, en cambio, que si la imagen proporciona el contenido ideacional (semántico) y el texto consiste en etiquetas identificativas sobre lo representado por la imagen, estamos ante un caso de estatus independiente con relación semántica de exposición (etiquetas genéricas e imagen abstracta o tecnológica; por ejemplo, la imagen de las partes de una flor y sus respectivos nombres) o ejemplificación (texto más general; por ejemplo, la imagen de un edificio y los correspondientes nombres con especificaciones técnicas, artísticas, etc.).

${ }^{17} \mathrm{http}: / /$ www.abc.es/20120305/ciencia/abci-asteroide-cercano-jamas-detectado-201203050933.html
} 


\subsubsection{Estatus de complementariedad}

\subsubsection{Texto e imagen complementarios, proyección de locución}

A diferencia de las relaciones de estatus de independencia y subordinación, cuando el texto y la imagen son complementarios, ambos se combinan para formar un sintagma más amplio, esto es, una información más amplia. Tanto el texto como la imagen constituyen fragmentos de dicha información y la unidad del mensaje se consigue en un nivel de abstracción superior (Barthes [1964] 1997b: 41). En muchos casos, tanto la imagen como el texto desempeñan el papel de participantes en un tipo de proceso. El proceso, que normalmente se expresa lingüísticamente mediante un grupo verbal, puede ser implícito.

Este tipo de relación suele aparecer en las viñetas e ilustraciones gráficas que acompañan a algunas noticias en los periódicos en papel, en las que aparece representado algún personaje de la noticia hablando o pensando. La imagen del personaje representa al locutor o al sensor (el participante que experimenta el proceso) del proceso verbal (decir) o mental (pensar), el proceso se representa mediante el bocadillo o la nube de pensamiento y el texto dicho o pensado se expresa con palabras. Sin embargo, también es posible entender esta relación en los documentos audiovisuales que se incorporan en algunas noticias de medios digitales. El vídeo puede consistir en las declaraciones de algún personaje relevante en la noticia o en un reportaje. La parte de audio representa el texto y la parte visualizable, la imagen. La complementariedad viene dada por la necesidad de combinar ambas partes para alcanzar una interpretación completa de la información. La relación entre el texto y la imagen, en estos casos, es de proyección de locución, ya que se reproducen las palabras dichas por alguien.

Algunos ejemplos de este tipo de relación en la que se reproducen las palabras de un personaje relevante puede verse, por ejemplo, en los vídeos de estas noticias ${ }^{18}$ : $<$ http://www.abc.es/videos-otros/20120914/terroristas-asesinos-ninos-podran-1840538 417001.html>, <http://www.abc.es/videos-espana/20120125/aprueba-cadena-perpetuarevisable-1413819766001.html>. Un ejemplo de reportaje con reproducción de discurso

\footnotetext{
${ }^{18}$ Fecha de consulta de los vídeos: 15 de junio de 2014.
} 
incrustado puede ser el vídeo de esta noticia: <http://www.abc.es/20121024/espana/ abci-cgpj-informe-desahucios-201210241039.html>.

\section{Conclusiones}

En este trabajo, hemos aplicado el modelo intersemiótico de Martinec y Salway (2005) al análisis de la relación imagen-texto en piezas informativas de la versión digital del periódico $A B C$. Con este modelo de análisis, tratamos de dar cuenta de esta relación en función de: (i) el estatus que ocupan dentro de la pieza informativa en tanto que unidades semióticas en sí mismas (independencia, interrelación, dependencia); y (ii) la relación semántica entre estas unidades semióticas: extensión o proyección del significado.

Las piezas informativas del ámbito científico presentan una notable variedad de dispositivos visuales: fotografías, diagramas, infografías, vídeos. Asimismo, muestran una gran carga informativa. La mayoría de las piezas analizadas (figuras 1, 3, 5, 6, 7) muestran que, en ciencia, la obtención de determinadas imágenes constituye en sí misma un hecho noticiable. Los periodistas científicos informan sobre la captación o el desarrollo de una imagen que no había podido obtenerse hasta el momento y difunden la imagen que los adelantos tecnológicos permiten plasmar en la actualidad.

Por su parte, en las piezas informativas correspondientes al ámbito jurídico, la carga informativa recae casi exclusivamente en el texto de la noticia, de modo que los dispositivos visuales revisten escasa informatividad por sí mismos. Asimismo, la variedad de estos dispositivos es menor: se emplean fundamentalmente fotografías y vídeos. Estos últimos, además, recogen bien declaraciones de personas relevantes en la noticia o suponen un relato de un periodista del hecho noticiado, de modo que, a través del modo audiovisual, se vuelve a primar la información lingüística.

En cuanto a la relación entre la imagen y el texto en las piezas analizadas, suele ser compleja y puede extenderse, por lo general, a diferentes partes del texto: titular, pie de imagen, cuerpo de la noticia. Esta relación multinivel puede influir en el tipo de relación de estatus y lógico-semántica entre la imagen y el texto en cada caso, de modo que la imagen puede coactuar de forma independiente con el titular o el pie de foto $\mathrm{y}$ subordinarse al texto de la noticia, o viceversa. Igualmente, una parte del texto puede 
cumplir una función de exposición respecto de la imagen, mientras que otra expande el contenido de esta o lo amplía con información de tipo circunstancial. Con todo, las piezas del ámbito científico suelen presentar una relación entre imagen y texto más cohesionada, dado que, como apuntábamos antes, las noticias de este ámbito informan a menudo sobre descubrimientos en los que la imagen es un hecho en sí mismo y aporta una enorme carga conceptual. De este modo, pues, se confirma la hipótesis inicial que establecíamos en el apartado de objetivos.

En suma, como hemos tratado de demostrar en este estudio, el tipo de análisis aplicado en este trabajo a las noticias de los ámbitos informativos científico y jurídico permite perfilar de una manera más fiable y comprensiva los distintos tipos de anclaje que se producen entre el texto de la noticia y las imágenes que lo acompañan, así como la función comunicativa que desempeñan dentro de la noticia. No obstante, dado el carácter exploratorio de este trabajo -es un paso inicial en la implementación de este modelo en el análisis multimodal de piezas informativas de la prensa digital- las conclusiones son también necesariamente provisionales. Por ello, en próximos trabajos queremos ajustar el modelo de análisis al tipo de texto que constituye una noticia en la prensa digital ampliando el alcance del análisis. Por una parte, creemos que es imprescindible ampliar el rango de las unidades de análisis para poder dar cuenta de la relaciones de estatus y lógico semánticas entre los distintos elementos visuales que suelen aparecer en una noticia digital y unidades textuales que superan el nivel del complejo de cláusulas y el párrafo, esto es, el texto como unidad global o discurso multimodal. Por otra, consideramos que, para alcanzar una visión completa de la relación intersemiótica entre texto e imagen en el ámbito que hemos analizado, hay que contemplar, además de las relaciones lógicos-semánticas -que atañen a la metafunción ideacional de la noticia-, las relaciones pragmático-comunicativas que se establecen entre las imágenes y el texto (metafunción interpersonal). Al cabo, las imágenes comunican a menudo mucho más que contenido conceptual y apelan al interlocutor, revelan las intenciones del emisor, transmiten ideología y comunican actitudes. 
Bibliografía

Barthes, R. ([1961] 1997a): The photographic message. En: Barthes, R. (ed.), ImageMusic-Text. Londres: Fontana, 15-31.

Barthes, R. ([1964] 1997b): Rhetoric of the image. En: Barthes, R. (ed.), Image-MusicText. Londres: Fontana, 32-51.

Bednarek, M. y H. Caple (2012): News Discourse. Londres/Nueva York: Continuum.

Buxó, Ma J. (1999): ... que mil palabras. En: Buxó, Ma J., De la investigación audiovisual. Fotografía, cine, vídeo, televisión. Barcelona: Proyecto A Ediciones, 1-22.

Canavilhas, J. (2007): Webnoticias. Propuesta de modelo periodístico para la www. Covilha: Livros Labcom.

González Rodríguez, Mª J. (2003): Relaciones lógico-semánticas y su forma de expresión en el género noticia. Atlantis 25 (2), 55-69.

Halliday, M. A. K. (1985): An Introduction to Functional Grammar. Londres: Arnold.

Halliday, M. A. K. (1994): An Introduction to Functional Grammar. Londres: Arnold.

Hodge, R. y G. Kress (1988): Social Semiotics. Nueva York: Ithaca.

Jewitt, C. (2009): Different approaches to multimodality. En: Jewitt, C. (ed.), The Routledge Handbook of Multimodal Analysis. Londres: Routledge, 28-39.

Kress, G. (2010): Multimodality: A Social Semiotic Approach to Contemporary Communication. Londres: Routledge.

Kress, G. y D. Mavers (2005): Social semiotics and multimodal texts. En: Somekh, B. y C. Lewin (eds.), Research Methods in the Social Sciences. Londres: Sage, 172-179.

Kress, G. y T. van Leeuwen (1996): Reading Images. Londres: Routledge.

Kress, G. y T. van Leeuwen (2001): Multimodal Discourse. Londres: Routlege.

Martinec, R. y A. Salway (2005): A system for image-text relations in new (and old) media. Visual Communication 4 (3), 337-371.

Micó, J. L. y P. Masip (2008): Recursos multimedia en los cibermedios españoles. Trípodos 23, 89-105.

Royce, T. (2007): Intersemiotic complementarity: A framework for multimodal discourse analysis. En: Royce, T. y W. Bowcher (eds.), New Directions in the Analysis of Multimodal Discourse. Nueva Jersey: Erlbaum, 63-109.

Salaverría, R. (2005): Redacción periodística en internet. Pamplona: Eunsa. 
Salaverría, R. y F. Sancho (2007): Del papel a la Web. Evolución y claves del diseño periodístico en Internet. En: Larrondo Ureta, A. y A. Serrano Tellería (eds.), Diseño periodístico en Internet. Bilbao: Servicio Editorial de la Universidad del País Vasco, 207-239.

Unsworth, L. (2006): Towards a metalanguage for multiliteracies education: Describing the meaning-making resources of language-image interaction. English Teaching: Practice and critique 5 (1), 55-76.

Van Leeuwen, T. (1991): Conjunctive structure in documentary film and television. Continuum 5 (1), 76-114.

Vega Encabo, J. (2012): Los límites de la visibilidad: ciencia e imagen. En: García Varas, A. (ed.), Filosofía e(n) imágenes: interpretaciones desde el arte y el pensamiento contemporáneos. Zaragoza: Institución Fernando el Católico, 41-69.

Yúfera Gómez, I. (2013): Visualizar información. La relación entre el texto y la imagen en la prensa digital de tema científico y de tema jurídico. Red visual 18, 36-48.

Yúfera, I. y otros (2013): El léxico jurídico en el periodismo digital: mecanismos de clarificación. LEA 35 (2), 242-275.

Recibido: 30 de julio de 2014 Aceptado: 16 de noviembre de 2014 Publicado: 30 de noviembre de 2015 